\title{
TENSIONES EN TORNO A LA PARENTALIDAD EN EL SECTOR PÚBLICO: PRESTACIONES DE POSTNATAL PARENTAL Y DE SALA CUNA EN EXTENSIÓN*
}

\section{Pablo ARellano OrTiz ${ }^{* *}$}

RESUMEN: En este trabajo se desarrolla la protección de la parentalidad a propósito de la ley No 20.891. Se describe la nueva normativa para el permiso postnatal parental y los nuevos beneficios de sala cuna para padres funcionarios públicos, además, algunas evoluciones recientes en cuanto a la interpretación de los derechos de sala cuna por la Dirección del Trabajo y por la Contraloría General de la República. Se sostiene que existe una cierta tensión en la normativa que tiende hacia la parentalidad. Se concluye el trabajo haciendo notar las tensiones que se han producido y las diferencias en la regulación para el sector público.

PALABRAS CLAVE: Familia; Mujer; Parentalidad; Permiso postnatal parental; Sala Cuna

\section{TENSIONS AROUND FATHERHOOD IN THE PUBLIC SECTOR: POSTNATAL PARENTAL BENEFITS AND NURSERY BENEFITS EXTENSION}

ABSTRACT: In this essay, the protection of fatherhood is developed in relation to Chilean Law $\mathrm{N}^{\circ} 20.891$. It describes the new rules for postnatal parental leave and new nursery benefits for male public workers, as well as some recent developments regarding the interpretation of the right to nursery by the Dirección del Trabajo and by the Contraloría General de la República. It is argued that a certain tension in the rules that tend towards fatherhood exists. The paper concludes by noting that there have been tensions and differences in the regulation for the public sector.

KEY WORDS: Family; Women, Parentality; Postnatal parental leave; Nursery

\footnotetext{
* $\quad$ Fecha de recepción: 12 de mayo de 2016.

Fecha de aceptación: 5 de enero de 2017.

** Profesor de Derecho del Trabajo y de Seguridad Social, Pontificia Universidad Católica de Valparaíso (Chile). Dirección postal: Pontificia Universidad Católica de Valparaíso, Facultad de Derecho, Escuela de Derecho, Avenida Brasil 2950, segundo piso, Valparaíso, Chile. Correo electrónico: pablo.arellano@pucv.cl
} 
Sumario: Introducción. 1) Marco teórico de estudio 2) Ampliación del permiso postnatal parental a las funcionarias y a los funcionarios públicos. (2.1) Postnatal parental corregido para el sector público (2.2.) Titularidad del derecho a sala cuna: el padre funcionario público 3) Derecho a la sala cuna en expansión. (3.1.) Nuevo criterio en relación al bono compensatorio de sala cuna. (3.2.) Mantención de derecho: sala cuna y jardin infantil en ejercicio continuo y sin discriminación. 4) Colofón: Extensión y laboralización de la parentalidad. 5) Bibliografía.

\section{INTRODUCCIÓN}

El avance normativo de nuestro país en los últimos años en materia de maternidad y vida familiar ha sido destacado por la Organización Internacional del Trabajo (en adelante OIT). Se ha señalado que somos un caso relevante dentro de la región latinoamericana ${ }^{1}$. Debemos así señalar que esto no es producto del azar sino que de un efectivo avance en estas materias. Justamente sobre este proceso es que pretendemos referirnos en este trabajo, en el cual se pondrá el acento en recientes desarrollos e interpretaciones sobre la extensión de este tipo de beneficios.

Como cuestión previa, y a modo de presentación del tema, debemos indicar brevemente ciertos rasgos importantes en el contexto de esta normativa. En este sentido hemos señalado en publicaciones previas ${ }^{2}$ que la legislación social tal como se estructura en los años 1950, en la conjunción de derechos asociados al trabajo y de derechos otorgados por la seguridad social, se basó fuertemente en el llamado modelo del hombre breadwinner o del hombre proveedor, según el cual es el hombre quien trabaja a tiempo completo y aporta la comida para la familia, y la mujer se queda en casa para administrar el hogar y los niños ${ }^{3}$. Lo anterior se explica porque la legislación social se desarrolló en un contexto donde predominaba el trabajo industrial en Europa y en donde el trabajador masculino en este sector fue considerado como un beneficiario directo de los derechos que su relación de trabajo le entregaba ${ }^{4}$. Se considera, además, que es a través del hombre-trabajador que las prestaciones de seguridad social se

1 OIT (2015) Social protection for maternity: key policy trends and statistics / International Labour Office, Social Protection Department. - Geneva: ILO, 2015 (Social protection policy paper ; $\left.\mathrm{N}^{\circ} 15\right)$.

2 Arellano Ortiz, Pablo (2015) Lecciones de seguridad social. Santiago: Librotecnia, p. 99.

3 Ver: Esping Andersen, Gosta. (2007) "The sustainbility of welfare states into the 21st century”. En R. Vij (ed.): Globalisation and Welfare, a critical reader. Palgrave Macmillan, p. 52. LAMARCHE, Lucie (2002) "The right to social security in the international covenant on economic, social and cultural rights". En Chapman, Audrey y Russel, Sage (eds.): Core Ob- 
extienden a los otros miembros de la sociedad: la mujer y los hijos. Se entendía entonces un rol supuestamente secundario para la mujer dentro de la sociedad. Relegándola a funciones hogareńas y cuidados de los hijos. Compartimos lo que señala el profesor Caamaño en el sentido que el desarrollo paulatino de la legislación laboral a comienzos del siglo XX va asociado a lo que podemos llamar un "pecado original", consistente en un desincentivo de la contratación de mujeres y acentuando su rol en el cuidado de la familia y del hogar 5 .

Como señala el mismo autor, en la actualidad hay un cuestionamiento del modelo tradicional relativo a la distribución de tareas entre hombre y mujer ${ }^{6}$. La sociedad, principalmente la occidental, ha avanzado hacia nuevos paradigmas en este sentido, por lo que una visión tan restringida de las tareas de hombre y mujer ya no es sostenible.

A nuestro entender ${ }^{7}$, hoy es posible que nos encontremos frente a dos proveedores, uno masculino, predominante, y otro femenino, menos importante en número, pero presente. Sin embargo, también puede suceder que ambos modelos se mezclen, ello se da en el caso en que ambos, tanto el hombre como la mujer, trabajen y aporten a la sobrevivencia de su hogar. Esto nos llevaría a concluir que no se trataría tan solo de una cuestión contractual de las relaciones patrimoniales entre cónyuges, sino que también de la relación de los modelos de protección dentro de la familia existentes en una sociedad.

Es justamente aquí donde buscamos situar la protección que entregan las medidas de parentalidad concebida desde una visión amplia. Para la OIT la parentalidad es descrita de la siguiente manera: "Mientras que el permiso de maternidad tiene como objetivo proteger a las trabajadoras durante el embarazo y la recuperación del parto, el permiso parental se refiere a una licencia por un plazo relativamente largo a disposición de uno o ambos padres, lo que les permite cuidar de un bebé o un niño pequeño en un periodo de tiempo, por lo general después del periodo de licencia de maternidad o paternidad'8. Se trata entonces de una concepción que va más allá del pe-

ligations: Building a Framework for Economic, Social and Cultural Rights. Antwerp-OxfordNew-York: Intersentia, p. 90.

5 CaAmaño Rojo, Eduardo (2010) "Mujer y trabajo: origen y ocaso del modelo del padre proveedor y la madre cuidadora". Revista de Derecho de la Pontificia Universidad Católica de Valparaiso, N XXXIV, pp. 179-209, p. 186.

6 CaAmaño Rojo, Eduardo (2008) "El permiso parental y la progresiva inclusión del padre trabajador en los derechos para la conciliación de trabajo y vida familiar”. Revista de Derecho de la Pontificia Universidad Católica de Valparaíso, N XXXI, pp. 325-354, p. 329.

7 Arellano (2015) 100.

8 OIT (2014) Maternity and paternity at work: law and practice across the world. Ginebra: International Labour Office, p. 60. 
ríodo de embarazo o postparto, se busca una protección basada en el bebé o infante, ya no solo de la madre, sino que de ambos padres. Así, la legislación les permite a uno o a los dos poder tomarse un tiempo para poder criar a su hijo/a. Sin lugar a dudas se trata de un cambio de paradigma en relación al modelo del hombre proveedor.

Sin embargo, el permiso parental no está incluido cómo tal en ningún convenio de la OIT $^{9}$. Pero, por otro lado, la Recomendación No 191 (que acompaña al Convenio No 183 sobre la protección de la maternidad) y la Recomendación No 165 (que acompaña a los trabajadores con responsabilidades familiares, 1981, $\mathrm{N}^{\circ}$ 156) contienen disposiciones sobre el permiso parental. El carácter vinculante de este último instrumento hace que su desarrollo en las legislaciones nacionales sea lento.

Como nos señala el profesor Caamaño, dentro de la legislación chilena no existen normas laborales que protejan a la mujer por el solo hecho de ser tal. El Código del Trabajo parte del supuesto de la igualdad formal entre mujeres y hombres en el trabajo, como lo confirman el artículo 2 y el nuevo texto del artículo 62 bis de ese cuerpo legal, en concordancia con el artículo 19 No 2 y No 16 inciso 3 de la Constitución Política de la República, que reconocen la igualdad de hombres y mujeres ante la ley y prohíben la discriminación en el empleo ${ }^{10}$.

Pero, por otro lado, la legislación chilena ha sido destacada, como señalamos, por ir incorporando medidas tendientes a equilibrar los derechos entre hombres y mujeres en relación a su vida familiar. Tenemos una legislación sobre protección de la maternidad bastante importante ${ }^{11}$, en la que se incorporó un permiso paternal hace algunos años ${ }^{12}$ y lo más reciente, y que ha producido una gran revolución, es la incorporación de un permiso postnatal parental ${ }^{13}$.

No obstante estos importantes avances legislativos han mostrado que ciertos beneficios no entregan una efectiva protección. En ese sentido la

9 En relación a las normas sobre protección de la maternidad de la OIT ver CAAMAÑo (2008) 333 y ss.

10 CaAmaño (2010) 196.

11 Ver: Naranjo Carvacho, Carmen Luisa (2011) "Regulación en Chile de los subsidios por incapacidad laboral común y maternal”. En Rojas Miño, Irene (Coordinadora): Cincuenta años de la Sociedad Chilena de Derecho del Trabajo y de la Seguridad Social: Homenaje Sociedad Chilena de Derecho del Trabajo y de la Seguridad Social, Chile. Santiago de Chile: AbeledoPerrot-LegalPublishing, pp. 391-416; Meza LunA, Ana (2004) "Protección a la maternidad y desigualdad laboral de la mujer”. Revista Laboral Chilena, N 5, p. 75.

$12 \mathrm{Al}$ respecto ver CaAmaño (2008) 346 y ss.

13 Ver: Cifuentes Lillo, Hugo; Arellano Ortiz, Pablo y Walker Errázuriz, Francisco (2011) "Protección por maternidad y permiso postnatal parental". Revista Laboral Chilena, $\mathrm{N}^{\circ} 201$, pp. 45-55. 
ley de postnatal parental redujo considerablemente el monto del subsidio que recibían los funcionarios públicos durante dicho periodo de tiempo. Lo que conllevó la molestia de muchas funcionarias públicas que se vieron forzadas a recibir un ingreso menor. A lo anterior se debe sumar una realidad compleja en relación al acceso a una sala cuna para la mujer trabajadora.

Si bien el modelo del hombre proveedor puede seguir presente en nuestra sociedad, este modelo no es la única forma de organización ${ }^{14}$. Entonces, postulamos que si bien existen evoluciones recientes, estas revelan una cierta tensión en el desarrollo de este derecho a través de sus avances, por un lado en relación a los sujetos que se pueden ver beneficiados, caso de las funcionarias publicas en relación al permiso postnatal parental y, por otro lado, en cuanto a la interpretación por parte de la administración, en relación al acceso a la sala cuna.

Esta tensión que se constata lleva a considerar cuál es el verdadero avance en materia de parentalidad en nuestra legislación. A fin de poder responder a esta última afirmación se comenzará este análisis con una breve revisión metodológica sobre el marco conceptual sobre el cual se desarrollará luego nuestra conclusión.

\section{1) MARCo Teórico del ESTUdio}

Como lo hemos venido señalando, la relación de equilibrio entre hombres y mujeres en materia laboral resulta de vital importancia para un buen ambiente familiar.

Este viejo conflicto entre responsabilidades familiares y laborales subyace en el ordenamiento jurídico vigente y representa la causa de las dificultades para asegurar una efectiva igualdad de oportunidades entre hombres y mujeres en el ámbito laboral ${ }^{15}$. En este sentido, la OIT ha señalado que de no mediar respuestas adecuadas a las tensiones entre vida familiar y laboral, pueden profundizarse las desigualdades socioeconómicas y de género, con consecuencias dañinas para la equidad y el desarrollo en la región latinoamericana ${ }^{16}$.

Caamańo nos aclara que la búsqueda por alcanzar mayores grados de armonización de trabajo y vida familiar no se limita únicamente a pro-

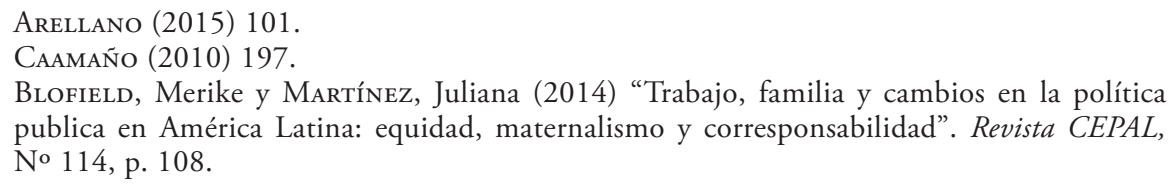


mover una mayor participación laboral femenina, así como a precaver y a sancionar actos de discriminación basados en el sexo, sino que busca, también, reivindicar el derecho de los trabajadores varones a vivir más intensamente el cuidado de sus familias, permitiéndoles que puedan conciliar efectivamente sus responsabilidades laborales y familiares. Así nos agrega el mismo autor que se trata entonces de poner de manifiesto que la conciliación de la vida laboral y familiar no incumbe únicamente a hombres y mujeres, sino que a toda la sociedad. Pero, en lo que atañe a esta rama del derecho, debe destacarse que el Derecho del Trabajo ha comenzado reconocer en el último tiempo la demanda creciente para armonizar trabajo y vida familiar, por la vía de incluir al padre trabajador como titular de derechos específicos en este sentido en la legislación laboral ${ }^{17}$. Por lo tanto, el juego en definitiva se trata de poder conciliar una regulación distinta para la mujer rompiendo los paradigmas iniciales, y a la vez incorporar derechos bajo un supuesto distinto para el hombre.

El punto clave de este razonamiento entonces es como poder realizar esta armonización y que las medidas se encausen en la obtención de este fin buscado. Al respecto nos interesa tener en cuenta la clasificación de medidas propuestas por Blofield y Martínez, la cual distingue tres tipos de medidas de políticas públicas relevantes para conciliar la vida familiar y laboral, a saber ${ }^{18}$ :

- Las políticas secuenciales, las cuales se refieren a medidas que protegen la seguridad de los ingresos durante períodos mensuales, semanales o diarios, destinados a los cuidados. Aquí se incluyen las licencias por maternidad, por paternidad y las parentales, pero también políticas de flexibilidad horaria y de trabajo de tiempo parcial. La secuenciación puede durar meses e involucrar muchos días de trabajo, como lo es en la licencia de maternidad, o durar horas dentro de una misma jornada semana laboral, como en el caso del trabajo de tiempo parcial o de cierto tipo de jornadas flexibles, respectivamente.

- Las políticas de desfamiliarización de los cuidados se refieren a transferencias y servicios que delegan responsabilidades de cuidado desde las familias, y concretamente desde las mujeres, a servicios con alguna intervención estatal. Estos pueden brindarse de forma directamente pública, conllevar incentivos o subsidios para la prestación privada, o bien legislar la prestación obligatoria de subsidios, servicios o de ambos por parte de empleadores y empleadoras.

Blofield/Martínez (2014) 109. 
- Las políticas relativas a las regulaciones con respecto a la contratación de cuidados provistos de manera remunerada desde el hogar que, precisamente por ello, transforman el domicilio en lugar de trabajo. La contratación individual de personal mayoritariamente femenino para trabajos en el ámbito doméstico es una alternativa al servicio prestado desde instituciones dedicadas a los cuidados, con implicaciones distintas para el papel que el Estado asume en materia de cuidados de "desfamiliarización" y de mercantilización, respectivamente, puesto que generalmente la regulación del trabajo doméstico remunerado no está incluida bajo el concepto de políticas de conciliación entre trabajo y responsabilidades familiares.

Para estas mismas autoras Blofield y Martínez, las concepciones pueden estar basadas en un enfoque desde el punto de vista de la desigualdad de género ${ }^{19}$. En la literatura sobre estados de bienestar y relaciones de género, señalan, se distingue entre políticas "maternalistas" y aquellas que promueven "corresponsabilidad social" en materia de cuidados ${ }^{20}$.

Bajo esta perspectiva encontramos como contrapunto al maternalismo la corresponsabilidad, la cual redistribuye responsabilidades de cuidados, tanto de las familias al Estado (corresponsabilidad estatal) como de las mujeres a los hombres (corresponsabilidad paterna). Se estima entonces que al asignar más responsabilidades de cuidado al Estado y a los padres, estas políticas tienen la capacidad de reducir las inequidades de género en la carga asistencial. Es bajo este supuesto de corresponsabilidad que encontramos la noción de parentalidad como un mecanismo igualitario de repartición de responsabilidades.

Un reciente estudio de la $\mathrm{OIT}^{21}$ muestra que los sistemas de permiso parental difieren significativamente de un país a otro. Así se puede encontrar una variación considerable en términos de elegibilidad, el pago, la duración, la posible flexibilidad en el uso, la edad del niño a ser cuidado y capacidad de transferencia entre los padres. En general, se constató que la duración del permiso parental es más largo que el de la licencia de maternidad, pero el pago es a menudo más bajo o no pagado del todo. Este tipo de mecanismos se preocupan de la sociedad en un sentido amplio, teniendo en cuenta el desarrollo del niño, el bienestar familiar, la fertilidad, la oferta de trabajo, la equidad de género y la distribución del ingreso.

El mismo estudio da cuenta que en algunos países, los permisos parentales largos pueden ser vistos como un medio de apoyo a la prestación

\footnotetext{
19 Blofield/Martínez (2014) 111.

20 OIT/PNUD (2009).

$21 \quad$ OIT (2014) 61.
} 
de atención de los padres para los niños pequeños, reduciendo así la necesidad de servicios de cuidado infantil, en particular respecto de los niños pequeños para los que dichos servicios pueden ser relativamente caros. Sin embargo, los permisos prolongados de los padres son tomados principalmente por las mujeres y pueden debilitar su posición en el mercado de trabajo y exacerbar las desigualdades de género, tanto en el campo laboral como en la división del trabajo en la familia y el hogar.

Una vez sentadas estas bases teóricas, procederemos a hacer una revisión de los recientes cambios en materia relativos a conciliación de la vida familiar, buscando poner acento en la ampliación de la parentalidad en nuestra legislación social.

\section{2) AMPliación DEL PERMiso pOSTNATAL PARENTAL A LAS FUNCIONARIAS Y A LOS FUNCIONARIOS PÚBLICOS}

Al hablar de ampliación hay que distinguir si se incluye a más beneficiarios o si se mejora la cobertura existente. Teniendo esto en cuenta la Ley $\mathrm{N}^{\circ} 20.891$, de $2016^{22}$, sobre perfeccionamiento del permiso postnatal parental y el ejercicio del derecho a sala cuna (en adelante, Ley $\mathrm{N}^{\circ}$ 20.891), tal como su nombre lo indica viene a perfeccionar el permiso postnatal parental para los funcionarios y funcionarias públicos. Se trata de una mejora importante de la situación existente. Además la misma Ley mejora la situación de dichos funcionarios en relación al ejercicio del derecho a la sala cuna.

\section{(2.1) POSTNATAL PARENTAL CORREgIDO PARA EL SECTOR PÚBLICO}

Por Ley $\mathrm{N}^{\circ} 20.545$, de $2011^{23}$, sobre protección de la maternidad y permiso postnatal parental (en adelante, Ley $\mathrm{N}^{\circ} 20.545$ ), se introdujeron modificaciones al régimen de protección de la maternidad y demás normas vinculadas, en especial, las relativas al cuidado del menor recién nacido, los subsidios por incapacidad laboral asociados, así como a la extensión de estos derechos al padre biológico, adoptante o que tiene a un niño a su cuidado. La Ley No 20.545 no modifica sustancialmente el régimen de prestaciones por maternidad en la legislación chilena. De hecho, el postnatal, como tal, no sufre alteración.

Publicada en el Diario Oficial el 22 de enero de 2016,

Publicada en el Diario Oficial el 17 de octubre de 2011. 
Lo que se hizo fue incorporar una nueva prestación denominada Permiso postnatal parental ${ }^{24}$ incorporando el artículo 197 bis al Código del Trabajo. Se trata entonces de un nuevo derecho para la mujer, consistente en un permiso adicional al descanso postnatal, de carácter irrenunciable. Así como el postnatal está referido al cuidado del hijo y también de la madre, este permiso adicional se puede compartir con el padre del menor, para atender al cuidado, primera educación y apego del nińo, tal como se buscaba en el mensaje de su proyecto de ley. Este permiso se extiende por 12 semanas a continuación del descanso postnatal, si se hace uso de él a tiempo completo, o de 18 semanas, si se opta por tomarlo por mitad de jornada. Hecha la opción por una de las dos modalidades, no es posible modificarla. Cualquiera sea el subsidio que reciba la trabajadora (por jornada completa o mitad de ella, según la opción), este reúne las características de un subsidio de incapacidad laboral asociado a la maternidad, y por consiguiente su fórmula de cálculo, tiene alguna variante específica

Ahora bien, para el caso de las y los funcionarias públicos, estos en principio tienen también derecho al postnatal parental en los mismos términos que los trabajadores del sector privado. Sin embargo, se había producido una diferencia en el monto de los dineros a percibir por parte de estos trabajadores. Ello debido a que estos funcionarios tienen derecho a remuneración íntegra, sin el tope de cotizaciones como límite, mientras hacen uso de licencia médica, sea por enfermedad común o maternidad ${ }^{25}$. Pero, la Ley No 20.545 en su artículo 6 no hizo aplicable al permiso postnatal parental el artículo 153 del D.F.L. No1, del Ministerio de Salud, de $2005^{26}$, que fija el texto refundido, coordinado y sistematizado del Decreto Ley $\mathrm{N}^{\circ} 2.763$, de 1979 y de las leyes $\mathrm{N}^{\circ} 18.933$ y N 18.469 (en adelante D.F.L. $\mathrm{N}^{\circ} 1$, de 2005). Con lo cual durante este periodo de 3 meses el monto de las prestaciones para un grupo de trabajadoras y trabajadores del sector público disminuyó considerablemente. Dicha interpretación fue refrendada por la Superintendencia de Seguridad Social (en adelante SUSESO) en su Circular 2777, donde ha señalado que a este permiso no le será aplicable lo dispuesto en el art. 153 del D.F.L. 1 de 2005 de Salud.

Ante múltiples reclamos por parte de las distintas asociaciones de funcionarios del sector público es la que la Ley No 20.891 en su artículo

\footnotetext{
24 Para mayor detalle sobre esta prestación ver Cifuentes/Arellano/WaLker (2011) 45 y 55.

25 Si bien para el pago del subsidio tanto en el caso de enfermedad común como de la maternidad se debe tramitar una licencia médica, en términos efectivos solo en el caso de la enfermedad común el beneficiario se encuentra padeciendo alguna dolencia. La maternidad no es bajo ningún respecto una enfermedad, tan solo se utiliza el vehículo administrativo de la licencia médica para efectos de tramitar el subsidio respectivo. 
1 viene a corregir esta situación, eliminado de la Ley No 20.545 la exclusión que se contemplaba en su artículo 6, incorporándolo en forma expresa al famoso artículo 153 del D.F.L. 1 de 2005 de Salud, quedando este con la siguiente redacción:

"Artículo 153.- El derecho a licencia por enfermedad, descanso de maternidad o enfermedad grave del hijo menor de un año y el derecho a permiso postnatal parental del personal afecto a la ley $N^{\circ} 18.834$, cuyo texto refundido, coordinado y sistematizado se fijó por el Decreto con Fuerza de Ley $N^{\circ}$ 29, de 2004, del Ministerio de Hacienda, se regirá por lo establecido en dicho cuerpo legal.

Estos trabajadores tendrán derecho, durante el goce de la licencia y el permiso postnatal parental, a la mantención del total de sus remuneraciones $y$ su pago corresponderá al Servicio o Institución empleadora, sin perjuicio de lo dispuesto en el artículo 12 de la Ley $N^{\circ} 18.196$.

La parte de sus remuneraciones sobre la que no han efectuado cotización para los efectos de esta ley, será de cargo exclusivo del Servicio o Institución empleadora".

La importancia de esta llamada corrección por la ley de 2016 radica en un aumento de dinero para quienes gocen de permiso postnatal parental en el sector público. Y en la recuperación de un importante beneficio para esta categoría de trabajadores que no veían afectados sus ingresos por el hecho de gozar de una licencia, no importando el motivo de esta.

Sin embargo, además de realizar esta corrección, la Ley No 20.891 procede a introducir una serie de modificaciones a otros cuerpos legales a fin de dejar muy en claro que esta categoría de trabajadores no verán afectados sus ingresos cuando se encuentren haciendo uso del permiso postnatal parental.

Las normas modificadas son las siguientes con sus textos actuales:

- El artículo 12 de la Ley No 18.196.

"Articulo 12.- A contar del $1^{\circ}$ de enero de 1983, respecto de los trabajadores regidos por el decreto con fuerza de Ley $N^{\circ} 338$, de 1960, afiliados a una institución de salud previsional y que se acojan a licencia médica por causa de enfermedad de acuerdo con el artículo 94 de dicho decreto con fuerza de ley, la Institución de Salud Previsional deberá pagar al Servicio o Institución empleadora una suma equivalente al minimo del subsidio por incapacidad laboral que le habría correspondido al trabajador de haberse encontrado este afecto a las disposiciones del decreto con fuerza de Ley $N^{\circ} 44$, de 1978, del Ministerio del Trabajo y Previsión Social.

A contar del $1^{\circ}$ de enero de 1984, el Fondo Nacional de Salud deberá pagar al Servicio o Institución empleadora, igual suma respecto de los fun- 
cionarios que hagan uso del referido beneficio y que no estén afiliados a una Institución de Salud Previsional.

Lo dispuesto en este artículo se aplicará en los mismos términos respecto de los funcionarios que hagan uso del permiso postnatal parental a que se refiere el artículo 197 bis del Código del Trabajo.

Los pagos que correspondan conforme a los incisos anteriores deberán ser efectuados dentro de los diez primeros dias del mes siguiente a aquel en que se haya ingresado la presentación de cobro respectiva.

Las cantidades que no se paguen oportunamente, se reajustarán en el mismo porcentaje en que hubiere variado el indice de precios al consumidor, determinado por el Instituto Nacional de Estadisticas, entre el mes anterior a aquel en que debió efectuarse el pago y el precedente a aquel en que efectivamente se realice y devengarán interés corriente".

- Los artículos 72 y 111 de la Ley No 18.834, sobre Estatuto Administrativo, cuyo texto refundido, coordinado y sistematizado fue fijado por el decreto con fuerza de Ley No 29, de 2004, del Ministerio de Hacienda.

"Artículo 72.- Por el tiempo durante el cual no se hubiere efectivamente trabajado no podrán percibirse remuneraciones, salvo que se trate de feriados, licencias, permiso postnatal parental o permisos con goce de remuneraciones, previstos en el presente Estatuto, de la suspensión preventiva contemplada en el articulo 136, de caso fortuito o de fuerza mayor. Mensualmente deberá descontarse por los pagadores, a requerimiento escrito del jefe inmediato, el tiempo no trabajado por los empleados, considerando que la remuneración correspondiente a un dia, medio día o una hora de trabajo, será el cuociente que se obtenga de dividir la remuneración mensual por treinta, sesenta y ciento noventa, respectivamente.

Las deducciones de rentas motivadas por inasistencia o por atrasos injustificados, no afectarán al monto de las imposiciones y demás descuentos, los que deben calcularse sobre el total de las remuneraciones, según corresponda. Tales deducciones constituirán ingreso propio de la institución empleadora.

Los atrasos y ausencias reiterados, sin causa justificada, serán sancionados con destitución, previa investigación sumaria.

Artículo 111.- Se entiende por licencia médica el derecho que tiene el funcionario de ausentarse o reducir su jornada de trabajo durante un determinado lapso, con el fin de atender al restablecimiento de su salud, en cumplimiento de una prescripción profesional certificada por un médico cirujano, cirujano dentista o matrona, según corresponda, autorizada por el competente Servicio de Salud o Institución de Salud Previsional, en su caso. Durante su vigencia el funcionario continuará gozando del total de sus remuneraciones. 
Durante el periodo de permiso postnatal parental regulado en el articulo 197 bis del Código del Trabajo, los funcionarios que hagan uso de él también continuarán gozando del total de sus remuneraciones".

- Los artículos 69 y 110 de la Ley No 18.883, que aprueba el Estatuto Administrativo para Funcionarios Municipales.

"Artículo 69.- Por el tiempo durante el cual no se hubiere efectivamente trabajado no podrán percibirse remuneraciones, salvo que se trate de feriados, licencias, permiso postnatal parental o permisos con goce de remuneraciones, previstos en este Estatuto, de suspensión preventiva contemplada en el artículo 134, o de caso fortuito o fuerza mayor. Mensualmente deberá descontarse por los pagadores, a requerimiento escrito del jefe inmediato, el tiempo no trabajado por los empleados, considerando que la remuneración correspondiente a un dia, medio dia o una hora de trabajo, será el cuociente que se obtenga de dividir la remuneración mensual por treinta, sesenta y ciento noventa, respectivamente.

Las deduciones de rentas motivadas por inasistencia o por atrasos injustificados, no afectarán al monto de las imposiciones y demás descuentos, los que deben calcularse sobre el total de las remuneraciones, según corresponda. Tales deducciones constituirán ingreso propio de la municipalidad empleadora.

Los atrasos y ausencias reiterados, sin causa justificada, serán sancionados con destitución, previa investigación sumaria.

Artículo 110.- Se entiende por licencia médica el derecho que tiene el funcionario de ausentarse o reducir su jornada de trabajo durante un determinado lapso, con el fin de atender al restablecimiento de su salud, en cumplimiento de una prescripción profesional certificada por un médico cirujano, cirujano dentista o matrona, según corresponda, autorizada por el competente Servicio de Salud o Institución de Salud Previsional, en su caso. Durante su vigencia el funcionario continuará gozando del total de sus remuneraciones.

Durante el periodo de permiso postnatal parental regulado en el artículo 197 bis del Código del Trabajo, los funcionarios que hagan uso de él también continuarán gozando del total de sus remuneraciones".

- El artículo único de la Ley No 19.117, que establece normas para la recuperación por municipalidades o corporaciones empleadoras de sumas correspondientes a subsidios por incapacidad laboral de funcionarios que señala,

"Artículo único. - Los Servicios de Salud, las Instituciones de Salud Previsional y las Cajas de Compensación de Asignación Familiar, deberán pagar a la respectiva Municipalidad o Corporación empleadora respecto de sus funcionarios regidos por la ley $N^{\circ} 18.883$ o de los profesionales de la educación regidos por el artículo 36, inciso tercero, de la Ley $N^{\circ} 19.070$, acogidos a 
licencia médica por enfermedad, una suma equivalente al subsidio que le habría correspondido al trabajador conforme con las disposiciones del decreto con fuerza de ley $N^{\circ} 44$, de 1978, del Ministerio del Trabajo y Previsión Social. Lo dispuesto en este artículo se aplicará en los mismos términos respecto de los trabajadores antes señalados que hagan uso del permiso postnatal parental a que se refiere el artículo 197 bis del Código del Trabajo.

Los pagos que correspondan conforme al inciso anterior deberán ser efectuados dentro de los diez primeros dias del mes siguiente a aquel en que se haya ingresado la presentación de cobro respectiva.

Las cantidades que no se paguen oportunamente, se reajustarán en el mismo porcentaje en que hubiere variado el indice de precios al consumidor, determinado por el Instituto Nacional de Estadisticas, entre el mes anterior a aquel en que debió efectuarse el pago y el precedente a aquel en que efectivamente se realice y devengarán interés corriente.

Lo dispuesto en este artículo se aplicará a los subsidios que se devenguen a contar de la fecha de publicación de esta ley, aunque correspondan a licencias médicas iniciadas con anterioridad o constituyan prórrogas de otras anteriores.

A las cantidades que perciban las Municipalidades por aplicación de los incisos anteriores, no les regirá lo dispuesto en el artículo 11 de la ley $N^{\circ} 18.768$ ".

- El artículo 19 de la Ley No 19.378, que establece el Estatuto de Atención Primaria de Salud Municipal.

"Artículo 19. - En materia de accidentes en actos de servicio y de enfermedades contraidas en el desempeño de sus funciones, se aplicarán las normas de la ley $N^{\circ}$ 16.744, pudiendo las entidades empleadoras adherirse a las mutualidades de empleadores a que se refiere dicho cuerpo legal.

Las entidades administradoras de salud municipal podrán afiliar a su personal regido por esta ley a las Cajas de Compensación de Asignación Familiar, conforme con la legislación que regula esta materia.

El personal que se rija por este Estatuto tendrá derecho a licencia médica, entendida esta como el derecho que tiene de ausentarse o reducir su jornada de trabajo durante un determinado lapso, con el fin de atender al restablecimiento de la salud, en cumplimiento de una prescripción profesional determinada por un médico cirujano, cirujano dentista o matrona, según corresponda, autorizada por el competente Servicio de Salud o Institución de Salud Previsional, en su caso. Durante su vigencia, la persona continuará gozando del total de sus remuneraciones.

Los Servicios de Salud, las Instituciones de Salud Previsional y las Cajas de Compensación de Asignación Familiar pagarán, a la municipalidad o corporación empleadora correspondiente, una suma equivalente al subsidio que le habría correspondido al trabajador de acuerdo con las disposiciones del 
decreto con fuerza de ley $N^{\circ} 44$, de 1978, del Ministerio del Trabajo y Previsión Social.

Los pagos que correspondan conforme al inciso anterior deberán ser efectuados dentro de los diez primeros dias del mes siguiente a aquel en que haya ingresado la presentación de cobro respectiva. Las cantidades que no se paguen oportunamente se reajustarán en el mismo porcentaje en que hubiere variado el Índice de Precios al Consumidor, entre el mes anterior a aquel en que debió efectuarse el pago y el precedente a aquel en que efectivamente se realizó, y devengará intereses corrientes.

A las cantidades que perciban las municipalidades por aplicación de los incisos anteriores, no les será aplicable lo dispuesto en el artículo 11 de la ley $N^{\circ} 18.768$.

El personal que se rija por este Estatuto y que haga uso del permiso postnatal parental regulado en el articulo 197 bis del Código del Trabajo continuará gozando del total de sus remuneraciones durante dicho permiso. Lo dispuesto en los incisos cuarto, quinto y sexto de este artículo se aplicará en los mismos términos respecto de los trabajadores antes señalados que hagan uso del permiso postnatal parental'.

- El artículo 38 de la Ley No 19.070, que aprueba el estatuto de los profesionales de la educación, cuyo texto refundido, coordinado y sistematizado fue fijado por el decreto con fuerza de Ley No1, de 1996, del Ministerio de Educación.

"Artículo 38: Tendrán derecho a licencia médica, entendida esta como el derecho que tiene el profesional de la educación de ausentarse o de reducir su jornada de trabajo durante un determinado lapso, con el fin de atender al restablecimiento de la salud, en cumplimiento de una prescripción profesional certificada por un médico cirujano, cirujano dentista o matrona, según corresponda, autorizada por el competente Servicio de Salud o Institución de Salud Previsional, en su caso. Durante su vigencia el profesional de la educación continuará gozando del total de sus remuneraciones.

Durante el periodo de permiso postnatal parental regulado en el articulo 197 bis del Código del Trabajo, los profesionales de la educación que hagan uso de él también continuarán gozando del total de sus remuneraciones".

- El artículo 18 del Decreto Ley No 3.529, de 1980, del Ministerio de Hacienda.

"Artículo 18. - Los servidores del Estado, regidos por el Código del Trabajo, que se acojan a subsidio de reposo preventivo, a licencia maternal, a permiso postnatal parental o a licencia por enfermedad común, tendrán derecho a percibir las remuneraciones no imponibles que les correspondieren, las que les serán pagadas por la respectiva entidad empleadora". 
- La letra a) del artículo $3^{\circ}$ de la Ley No 20.240 que perfecciona el sistema de incentivos al desempeño de los fiscales y de los funcionarios del Ministerio Público

"Artículo 3․- Tendrá derecho a percibir el bono de gestión institucional, el personal que cumpla los siguientes requisitos:

a) Que haya prestado servicios durante un plazo no inferior a seis meses, en forma continua o discontinua, en el año calendario en que debió cumplirse el Compromiso de Gestión Institucional. Para estos efectos, no se considerará tiempo efectivamente trabajado el correspondiente a los permisos sin goce de remuneraciones ni a licencias médicas con la sola excepción de los periodos originados por licencias médicas por accidentes del trabajo a que se refiere la ley $N^{\circ}$ 16.744, incluidos los descansos previstos en los artículos 195 y 196, así como el permiso postnatal parental del artículo 197 bis, todos del Código del Trabajo".

- El artículo $4^{\circ}$ de la Ley No 19.531 que reajusta e incrementa las remuneraciones del Poder Judicial; modifica el decreto Ley No 3.058 de 1979; crea el departamento de recursos humanos en la Corporación Administrativa del Poder Judicial y modifica el Código Orgánico de Tribunales.

"Artículo 40.- Establécese, a contar del $1^{\circ}$ de enero de 2008, un bono de modernización para el personal perteneciente a los grados III al XI del Escalafón del Personal Superior del Poder Judicial, a los Escalafones de Consejeros Técnicos y de empleados del Poder Judicial, a la Academia Judicial y a la Corporación Administrativa del Poder Judicial, con los incrementos, modalidades y porcentajes que se indican en los artículos siguientes.

El bono de modernización contendrá los siguientes elementos:

a) Un componente base, de un 10\%;

b) Un incremento por desempeño institucional, de hasta un 7\%, de acuerdo a lo establecido en el artículo $4^{\circ}$ bis, $y$

c) Un incremento por desempeño colectivo, de hasta un 6\%, según lo que expresa el artículo $4^{\circ}$ ter.

El monto de este bono se determinará aplicando los porcentajes señalados precedentemente sobre la suma del sueldo base, la asignación judicial y la asignación profesional, en su caso, percibidas por cada funcionario a quien corresponda el beneficio, durante el periodo respectivo.

El componente base se pagará mensualmente. Los incrementos por desempeño institucional y colectivo se pagarán trimestralmente, en cuatro cuotas, en los meses de marzo, junio, septiembre y diciembre de cada año. El monto a pagar en cada cuota, será equivalente al valor acumulado en el trimestre respectivo, como resultado de la aplicación mensual de dichos incrementos.

No tendrán derecho a percibir los incrementos a que se refieren los literales b) y c) precedentes, los funcionarios que sean calificados en lista condicio- 
nal o deficiente, ni aquellos que, durante el año anterior al pago del mismo, no hayan prestado servicios efectivos en el Poder Judicial, en la Academia Judicial o en la Corporación Administrativa del Poder Judicial durante a lo menos seis meses, con la sola excepción de los periodos correspondientes a licencias médicas por accidentes del trabajo a que se refiere la ley $N^{\circ} 16.744$, incluidos los descansos previstos en los artículos 195 y 196, asi como el permiso postnatal parental del artículo 197 bis, todos del Código del Trabajo.

No obstante, el personal a quien corresponda los incrementos por desempeño institucional y por desempeño colectivo que deje de prestar servicios antes de completarse el trimestre respectivo, tendrá derecho a que estos incrementos se paguen en proporción a los meses completos efectivamente trabajados.

Los montos que se perciban por concepto del bono de modernización no servirán de base de cálculo de ninguna otra remuneración. Tendrán el carácter de tributables e imponibles para fines de previsión y salud. Para determinar los impuestos e imposiciones a que se encuentren afectos los incrementos por desempeño institucional y colectivo, se distribuirá su monto en los meses que comprenda el periodo que corresponda y los cuocientes se sumarán a las respectivas remuneraciones mensuales. Con todo, las imposiciones se deducirán de la parte que, sumada a las respectivas remuneraciones mensuales, no exceda del limite máximo de imponibilidad'.

De entre todos estos cuerpos normativos debemos destacar el efecto que producirá la modificación del artículo 18 del Decreto Ley No 3.529, de 1980, ya que implicará que trabajadores regidos por el Código del Trabajo obtendrán la prestación de postnatal parental sin tope manteniendo por completo sus remuneraciones. Existiendo dos niveles de prestaciones para trabajadores regidos por el Código del Trabajo. No se trata de que se elimine este beneficio, sino que se mejore la prestación y que ningún trabajador vea disminuidos sus ingresos durante el permiso postnatal parental.

\section{(2.2.) Titularidad Del Derecho A SAlA CUNA: El PADRE FUNCIONARIO PÚBLICO}

La Ley No 20.981 no solo realiza una corrección al permiso postnatal parental, también procede a regular, en sus artículos 12 y 13, un beneficio nuevo. Se trata de una regulación particular sobre el derecho a sala cuna.

En el artículo 12 se establece un nuevo supuesto para el beneficio de sala cuna. Señalándose que para el caso que ambos padres de un hijo menor de dos años sean funcionarios públicos de algún ministerio o servicio público que dependa o se relacione con el Gobierno a través de él, 
la madre va a poder elegir que su empleador cumpla con la obligación establecida en el artículo 203 del Código del Trabajo en la sala cuna que disponga el servicio público empleador del padre, siendo financiado por la institución empleadora de la madre, de conformidad a lo que establezca el reglamento. En otras palabras, si ambos padres son trabajadores del Estado, ellos podrán escoger a cual de las dos salas cunas llevar a su hijo menor de dos años.

Esto da por supuesto que ambos servicios cuenten con sala cuna. Lo que no siempre ocurre. Cuando ello no ocurre se sigue la lógica del Código del Trabajo en que el empleador debe realizar un convenio con una sala cuna acreditada por la Junta Nacional de Jardines Infantiles (JUNJI). Pero, en este caso, el legislador se pone en el supuesto que el empleador del padre tiene una sala cuna propia y de buena calidad y le permite al hijo/hija de este poder acceder a dicha sala cuna y no restringir el acceso solo a los hijos/hijas de sus trabajadoras madres.

Creemos que se trata de una ley muy interesante en términos de parentalidad y de igualación de derecho entre hombre y mujer en la crianza de los hijos. Sin embargo, se sigue manteniendo una fuerte tendencia a que la madre posee más derechos que el padre. Esto debido a que es la funcionaria quien opta por hacer uso del beneficio, es ella la que debe dar aviso a su empleador, la cual solicitará a la institución empleadora del padre la disponibilidad de cupo para ello. En caso de existir cupos limitados, el personal de la institución empleadora del padre tiene derecho preferente y la institución a la cual pertenece la funcionaria debe dar cumplimiento al derecho a sala cuna conforme lo dispuesto en el artículo 203 del Código del Trabajo.

Se establece que un reglamento dictado por el Ministerio de Hacien$\mathrm{da}^{27}$ establecerá la forma en que la funcionaria comunicará a su empleador el derecho a opción aquí descrito, la o las oportunidades en la cual podrá hacer uso del beneficio, los procedimientos a que deberán ajustarse las instituciones empleadoras de la madre y el padre y todas las demás normas necesarias para la aplicación de este artículo.

Para el caso que ninguno de los empleadores del padre o de la madre posean sala cuna, entonces ellos van a poder optar por la sala cuna del convenio de sus empleadores que más les convenga y no verse restringidos a una sola opción. Esto se colige del artículo 13, que establece que en el caso que ambos padres de un hijo menor de dos años sean funcionarios públicos de alguna municipalidad o universidad estatal, la madre pue-

27 Reglamento que al cierre de este trabajo aún no es dictado. 
de elegir que su empleador cumpla con la obligación establecida en el artículo 203 del Código del Trabajo en la sala cuna que disponga el servicio público empleador del padre, siempre que exista un convenio entre las instituciones empleadoras de la madre y el padre. Lo anterior también será aplicable cuando uno de los padres sea funcionario de las instituciones antes indicadas y el otro sea funcionario público de algún ministerio o servicio público que dependa o se relacione con el Gobierno a través de él. Nuevamente en este caso es la madre la que ejerce la opción.

Pero más allá de que se siga apoyando el rol de crianza que deba tener la mujer, esta ley entrega un beneficio que no poseen los trabajadores del sector privado. Sin lugar a dudas se hace en términos muy prácticos una ampliación de los beneficiarios del derecho a sala cuna, bajo un nuevo supuesto. Se trata de una norma mucho más favorable que las contenidas en el Código del Trabajo.

\section{3) DERECHO A LA SALA CUNA EN EXPANSIÓN}

No solo este nuevo texto normativo se ha referido al derecho a sala cuna. Recientes pronunciamientos por parte de órganos administrativos se han referido a este derecho. Dichos órgano son la Dirección del Trabajo y la Contraloría General de la República. Ambas instituciones vienen a señalar nuevos criterios que consideramos como ilustrativos de la tendencia a extender este derecho.

\section{(3.1.) NUEVO CRITERIO EN RELACIÓN AL BONO COMPENSATORIO DE SALA CUNA}

Sobre esta materia se ha pronunciado la Dirección del Trabajo emitiendo un pronunciamiento que viene a cambiar un criterio ya existente. Se trata del Dictamen No 6758 / 086 del 24 de diciembre de 2015 de dicho órgano administrativo.

Cabe tener presente que en esta materia, en principio no resulta jurídicamente procedente autorizar el otorgamiento de un bono compensatorio del beneficio de sala cuna como modalidad de cumplimiento del derecho establecido en el artículo 203 del Código del Trabajo, toda vez que el empleador está obligado a cumplir con su obligación a través de una de las tres alternativas previstas en dicha disposición legal, de modo tal que si una de ellas se torna imposible deberá cumplir con aquella que 
resulta factible ${ }^{28}$. Sin embargo, en un reciente Dictamen de la Dirección del Trabajo ${ }^{29}$ se ha cambiado dicho criterio señalando que el certificado expedido por un facultativo competente, que prescriba que la asistencia de un menor a establecimientos de sala cuna no resulta recomendable atendidas sus condiciones de salud, constituye un antecedente suficiente, para que las partes, si así lo consideran, acuerden el otorgamiento de un bono compensatorio del beneficio de sala cuna, no siendo necesario un análisis ulterior de esta Dirección de un pacto en tal sentido. De esta manera se reconsidera doctrina vigente respecto de las autorizaciones que entrega la Dirección para que las partes acuerden el otorgamiento de un bono compensatorio de sala cuna atendidas las condiciones de salud del menor, contenida, entre otros, en Ordinarios $\mathrm{N}^{\circ} 4257$ de 28 de octubre de 2011 y 701 de 7 de febrero de 2011.

La Circular $\mathrm{N}^{\circ} 11,19.01 .16$, imparte instrucciones específicas sobre tramitación de solicitudes de autorización de bono compensatorio de sala cuna, conforme a nuevo criterio contenido en Dictamen $\mathrm{N}^{\circ} 6.758 / 086$, 24.12.15.

\section{(3.2.) MANTENCIÓN DE DERECHO: SALA CUNA Y JARDÍN INFANTIL EN EJERCICIO CONTINUO Y SIN DISCRIMINACIÓN}

En este acápite partiremos de la base del criterio ya sentado de la Contraloría en el sentido que los jardines infantiles constituyen prestaciones de seguridad social a las que pueden acceder los niños hasta la edad de su ingreso a la educación general básica y que, dado que no existe un mandato legal que obligue a los entes estatales a considerar dicha prerrogativa para los hijos de su personal, es facultativo para ellos otorgarlo dentro del ámbito de sus disponibilidades presupuestarias. A ello, dicho órgano fiscalizador ha agregado que una vez acordado por el empleador, debe extenderse a todos los menores en edad de gozar del mismo, sin discriminaciones, conforme a reglas de carácter objetivo, no pudiendo excluirse a ninguno de ellos ${ }^{30}$.

28 Ordinario de la Dirección del Trabajo No 4682 de 26 de noviembre de 2014. Mismo sentido: Ordinario de la Dirección del Trabajo $N^{\circ} 4641$ de 24 de noviembre de 2014.

29 Dictamen de la Dirección del Trabajo Nº 6758/086 de 24 de diciembre de 2015.

30 Como se enuncia en el Dictamen N 3.413 de la Contraloría General de la República de 14 de enero de 2016. Dicho criterio además es vuelvo a mencionar en el Dictamen $N^{\circ} 12.291$ de la Contraloría General de la Republica de 16 de febrero de 2016 en el que se pronuncia sobre el cierre de jardín infantil y sala cuna institucional, durante el mes de febrero de 2016, lo que no contraviene normativa sobre 
Entonces, cabe sostener que los beneficios que se establezcan en relación a la sala cuna y el jardín infantil deben respetar criterios objetivos y de no discriminación, no pudiendo considerarse la edad como un criterio diferenciador. He aquí lo relevante de esta jurisprudencia, ello porque un niño hijo de una funcionaria que hace uso de la sala cuna institucional al crecer sigue en el jardín infantil, el cual pudiere ser apartado por cumplir una cierta edad. Cabe notar que la sala cuna y jardín infantil son, casi por regla general, la misma institución. No se trata de dos prestadores distintos, sino que de uno que ofrece dos servicios.

A este respecto el Dictamen $N^{\circ} 3.413$ de la Contraloría General de la República de 14 de enero de 2016 viene a pronunciarse sobre tres cuestiones de interés práctico que a nuestro parecer confirman la tendencia enunciada de extensión de beneficios parentales.

El pronunciamiento se realiza a propósito de una consulta realizada por el Director Nacional del Instituto Nacional de Propiedad Industrial (INAPI). El cual pregunta si puede reembolsar a sus funcionarias las sumas que ellas hubieren desembolsado por concepto de pago de jardín infantil para sus hijos, cuando se ha verificado alguna de las siguientes circunstancias:

- Cuando se deja de solventar estas prestaciones a los hijos de sus trabajadoras que cumplieron seis años de edad mientras permanecían en este nivel educacional.

- Cuando las funcionarias matriculan a sus hijos en establecimientos que se encuentran fuera del convenio con que se cuenta, lo que atiende al interés de que cursen en el mismo plantel los demás niveles de enseñanza.

- De aceptarse la procedencia de estos reembolsos, pide que se precise si ello puede realizarse con efecto retroactivo.

$\mathrm{Al}$ respecto se procede a dar una respuesta a cada una de estas inquietudes.

En relación al primer punto, se indica "que la jurisprudencia de este origen ha informado que los hijos de servidores que se encuentren asistiendo a jardines infantiles -utilizando este beneficio-, y que cumplan seis años de edad mientras cursan el último año de educación preescolar, tienen derecho a finalizar el periodo lectivo respectivo en el establecimiento al que asisten, pudiendo permanecer en él hasta la fecha de ingreso a la educación general básica (aplica dictámenes $N^{\circ}$ s. 32.840, de 1997, 49.122, de 2010 y 15.166, de 2014, entre otros)".

la materia, en la medida en que se verifiquen las acciones para dar continuidad a esas prestaciones en los términos que indica. 
Se agrega que la legislación no contempla lapsos entre el jardín infantil y la entrada a la enseñanza básica, por lo que no podría dejarse al menor un año fuera del sistema.

En cuanto al pago, señala expresamente que "el INAPI debe hacer efectivo el señalado criterio, por lo que resulta procedente que pague en forma retroactiva este beneficio a las funcionarias que acrediten fehacientemente que vieron suspendida esta prestación por haber alcanzado sus hijos la edad de seis años, mientras asistian a un jardin infantil". Haciendo aplicable, por no haber norma expresa, el lapso de prescripción del artículo 2.515 del Código Civil, esto es, cinco años contados desde que fue impetrada esta prestación.

En relación al segundo punto, la Contraloría señala que "no se advierte inconveniente para que el INAPI reembolse los montos que sus funcionarias pagan por concepto de jardin infantil, cuando no optaren por alguno de los establecimientos previstos en el aludido convenio, en la medida que esa decisión no implique vulnerar el principio de la no discriminación antes referido". En todo caso se establece que el pago de este servicio deberá sujetarse a las mismas condiciones y requisitos dispuestos en el convenio que mantiene el INAPI.

Finalmente, en cuanto a la posibilidad de disponer el pago retroactivo de estos reembolsos, se recuerda que la jurisprudencia administrativa "ha determinado que una vez que los servicios publicos establezcan el beneficio de que se trata, este opera para el futuro, por lo que no procede que se disponga con efecto retroactivo".

Sin embargo, llama fuertemente la atención que para el caso en concreto del dictamen se señala que "la circunstancia de entregar este beneficio solo a aquellos menores cuyos padres optaron por jardines infantiles incluidos en el convenio que mantiene el INAPI para estos efectos, vulneraría la jurisprudencia de esta Contraloria General, según la cual esta prestación debe extenderse a todos los infantes en edad de gozar de esta, sin discriminaciones, conforme a reglas de carácter objetivo, no pudiendo excluirse a ninguno de ellos.

Considerando lo anterior, procede que, excepcionalmente, el INAPI reembolse los gastos por concepto de jardin infantil en que hubieren incurrido sus funcionarias que inscribieron a sus hijos en establecimientos que no integraban el convenio respectivo, pero solo a contar de la fecha en que se concedió esta prestación al resto de los servidores mediante la suscripción del referido instrumento".

Este dictamen por las distintas materias tratadas y por los alcances de estas resulta de vital importancia en materia de prestación de sala cuna 
y jardín infantil. Se abre la puerta para que el beneficio llegue hasta los 6 años. Para aquellas situaciones vigentes eventualmente podría haber un pago retroactivo. Y además, cabe la posibilidad de que estas condiciones se hagan en un establecimiento distinto de aquel del convenio con el servicio. Sin lugar a dudas se trata de una ampliación de las alternativas para los padres que facilita su conciliación de la vida familiar y laboral.

\section{4) COLOFÓN: EXTENSIÓN Y LABORALIZACIÓN DE LA PARENTALIDAD}

Las evoluciones legislativas y de interpretación administrativa sin lugar a dudas muestran un avance hacia una concepción de parentalidad más importante en nuestro país. Sin embargo, a la vez demuestra que entre hombres y mujeres sigue existiendo una gran diferenciación. Si bien el Estado avanza hacia una corresponsabilidad estatal, no se logra lo mismo en la corresponsabilidad paternal, ya que el padre sigue sin tener los mismos derechos que la madre. Una constatación importante es el nivel que han alcanzado dentro de los derechos de la parentalidad la regulación del derecho a la sala cuna para los funcionarios públicos. De hecho, retomando la terminología de Karla Varas, podríamos incluso señalar que esto se puede enmarcar dentro de una laboralización ${ }^{31}$ de los beneficios sociales en la función pública. Ello por cuanto los derechos de sala cuna se encuentran regulados por el artículo 203 del Código del Trabajo, pero sumado a las interpretaciones administrativas citadas, estos derechos para las y los trabajadores del sector público resultan más beneficiosos que para aquellos trabajadores del sector privado. Saludamos y admiramos las nuevas interpretaciones y desearíamos que estas fuesen también aplicables en el sector privado en un corto plazo.

En este sentido, las interpretaciones efectuadas por la Contraloría General de la República y por la Dirección del Trabajo a nuestro parecer no son contrapuestas. Se enmarcan dentro de un proceso de mejora y extensión de la parentalidad. Así, llamamos a los entes interpretadores a realizar sus labores mediante un diálogo de órganos para que esta tendencia se mantenga y no se produzcan inconsistencias.

31 Retomando el concepto ya acuñado en Varas Marchant, Karla (2013) "Laborización de la función pública: admisión de personal laboral”. Revista Estudios Laborales, No 9, pp. 131190; y Varas Marchant, Karla (2013) "El Código del Trabajo y la función pública: Análisis de la aplicación supletoria de la acción de tutela de derechos fundamentales”. Revista de Derecho Laboral y Seguridad Social, Vol. III, pp. 43-60. 
Las modificaciones de la Ley No 20.891 sin lugar a dudas mejoran la situación de los trabajadores del sector público. No solo porque vienen en corregir los efectos producidos por la Ley No 20.545, sino porque pone a estos trabajadores en una situación muy superior al sector privado al entregarles a los padres la posibilidad de escoger si sus hijos van a la sala cuna del empleador del padre o de la madre. La nueva regulación permite que exista una mejor conciliación de la vida familiar y laboral para el sector público.

La tendencia es hacia una mayor injerencia estatal y hacia la mayor corresponsabilidad del padre. Pero, la mujer sigue siendo considerada en su rol de madre criadora en vez de trabajadora. Como señala el profesor Caamaño, ese "pecado original" la sigue persiguiendo. A nuestro parecer, la corresponsabilidad paternal se consagra para el padre funcionario público, pero condicionado a que la madre lo deje intervenir. Queda por mejorar esto tanto a nivel legislativo como cultural.

Los cambios que a nuestro parecer deberían hacerse no son inmediatos. Requieren más que un cambio legislativo o de interpretación administrativa, se necesita de un cambio cultural. Las tensiones que estas temáticas generan pueden ser evitadas al regularse de la misma manera para sector público y para el sector privado. Pero por sobre todo entregando más y mejores derechos que permitan una efectiva parentalidad, una que contenga un apego efectivo y corresponsabilidad paternal real.

\section{BIBLIOGRAFÍA CITADA}

Arellano Ortiz, Pablo (2015) Lecciones de Seguridad Social. Santiago: Librotecnia.

Blofield, Merike y Martínez, Juliana (2014) “Trabajo, familia y cambios en la política publica en América Latina: equidad, maternalismo y corresponsabilidad". Revista CEPAL, No 114, diciembre, pp. 107-125.

CaAmaño Rojo, Eduardo (2010) "Mujer y trabajo: origen y ocaso del modelo del padre proveedor y la madre cuidadora". Revista de Derecho de la Pontificia Universidad Católica de Valparaíso, N ${ }^{\circ}$ XXXIV, pp. 179-209.

CaAmaño Rojo, Eduardo (2008) "El permiso parental y la progresiva inclusión del padre trabajador en los derechos para la conciliación de trabajo y vida familiar". Revista de Derecho de la Pontificia Universidad Católica de Valparaíso, No XXI, pp. 325-354. 
Esping Andersen, Gosta (2007) "The sustainability of welfare states into the 21 st century". En R. Vij (ed.): Globalisation and Welfare, a critical reader. Palgrave Macmillan.

LAMARCHE, Lucie (2002) "The right to social security in the international covenant on economic, social and cultural rights". En Chapman, Audrey, y Russel, Sage (eds.): Core Obligations: Building a Framework for Economic, Social and Cultural Rights. Antwerp-Oxford- NewYork: Intersentia, pp. 87-114.

OIT/PNUD (2009) Trabajo y familia, Hacia nuevas formas de conciliación con corresponsabilidad social. Santiago: Organización Internacional del Trabajo.

OIT (2014) Maternity and paternity at work: law and practice across the world. Ginebra: International Labour Office.

OIT (2015) Social protection for maternity: key policy trends and statistics / International Labour Office, Social Protection Department. Geneva: ILO, 2015 (Social protection policy paper; N ${ }^{\circ}$ $15)$.

Cifuentes lillo, Hugo; Arellano Ortiz, Pablo y Walker Errázuriz, Francisco (2011) "Protección por maternidad y permiso postnatal parental". Revista Laboral Chilena, N²01, pp. 45-55.

Naranjo Carvacho, Carmen Luisa (2011) "Regulación en Chile de los subsidios por incapacidad laboral común y maternal". En Rojas Mińo, Irene (Coordinadora): Cincuenta años de la Sociedad Chilena de Derecho del Trabajo y de la Seguridad Social: Homenaje Sociedad Chilena de Derecho del Trabajo y de la Seguridad Social, Chile. Santiago de Chile: AbeledoPerrot-LegalPublishing, pp. 391-416.

Meza Luna, Ana (2004) "Protección a la maternidad y desigualdad laboral de la mujer". Revista Laboral Chilena, $\mathrm{N}^{\circ} 5$.

Varas Marchant, Karla (2013) "Laborización de la función pública: admisión de personal laboral". Revista Estudios Laborales, No 9, pp. 131-190.

Varas Marchant, Karla (2013) "El Código del Trabajo y la función pública: Análisis de la aplicación supletoria de la acción de tutela de derechos fundamentales". Revista de Derecho Laboral y Seguridad Social, Vol. III, pp. 43-60. 